\title{
Endometrial polyps: Is the prediction of spontaneous regression possible?
}

\author{
Semra Yuksel, MD', Guray Tuna, MD', Hale Goksever Celik, MD², Suleyman Salman, MD' \\ Department of Obstetrics and Gynecology, ${ }^{1}$ Saglik Bilimleri University, Gaziosmanpasa Training and Research Hospital, Gaziosmanpasa/Istanbul, \\ ${ }^{2}$ Saglik Bilimleri University, Istanbul Kanuni Sultan Suleyman Training and Research Hospital, Küçükçekmece/Istanbul, Turkey
}

\section{Objective}

Endometrial polyps have been considered as a hyperplastic growth of endometrial stromal and glandular tissues. Even asymptomatic polyps in premenopausal women are usually removed as soon as they are diagnosed, although it is still unknown how often endometrial polyps disappear spontaneously. The aim of this study was to investigate the regression rate of endometrial polyps and the possible factors related to their spontaneous regression.

\section{Methods}

A total of 197 women with endometrial polyps were treated with operative hysteroscopy between January 2017 and April 2019 at our tertiary center. Of these, 123 patients who preferred conservative follow-up were enrolled in the study. Clinical and pathological data were obtained from electronic medical records.

\section{Results}

Patients with endometrial polyps were followed up for a median period of 62 days (range 30-360 days). Most women with endometrial polyps (84\%) were reported to have gynecologic symptoms. Spontaneous polyp regression was observed in $28(23 \%)$ patients who underwent surgery reevaluation. Patient age ( $<45$ years), premenopausal period, and polyp size $(<2 \mathrm{~cm})$ were found to be associated with spontaneous endometrial polyp regression $(P<0.05)$. We also observed more polyp regression in women with abnormal uterine bleeding $(P=0.05)$. Second-look hysteroscopy showed that all postmenopausal women had persistent endometrial polyps.

\section{Conclusion}

Patient age ( $<45$ years), premenopausal period, polyp size $(<2 \mathrm{~cm})$, and abnormal uterine bleeding may be associated with spontaneous endometrial polyp regression.

Keywords:

Polyps; Hysteroscopy; Intermenstrual bleeding; Adenomatous polyps

\section{Introduction}

Endometrial polyps have been considered as a hyperplastic growth of the stromal and glandular parts of the endometrium [1]. The prevalence of endometrial polyps in women is approximately $7.8 \%$. However, it seems to be higher (9.2\%) in women over the age of 30 years [2]. Most polyps are known to be benign, especially in premenopausal women. Estimates of endometrial cancer occurrence within polyps vary across study populations as $1.1-4.9 \%$ [3]. While endometrial polyps are usually asymptomatic, they may lead to intermenstrual bleeding, menorrhagia, postmenopausal bleeding, infertility, and pelvic pain.
Received: 2020.08.16. Revised: 2020.10.19. Accepted: 2020.11.05. Corresponding author: Semra Yuksel, MD

Department of Obstetrics and Gynecology, Saglik Bilimleri University, Gaziosmanpasa Training and Research Hospital, Street 885, Gaziosmanpasa/İstanbul 34255, Turkey

E-mail: drsemrayuksel@gmail.com

https://orcid.org/0000-0003-3773-4107

Articles published in Obstet Gynecol Sci are open-access, distributed under the terms of the Creative Commons Attribution Non-Commercial License (http://creativecommons. org/licenses/by-nc/3.0/) which permits unrestricted non-commercial use, distribution, and reproduction in any medium, provided the original work is properly cited.

Copyright $\odot 2021$ Korean Society of Obstetrics and Gynecology 


\section{Obstetrics \& Gynecology Science}

Semra Yuksel, et al. Regression of endometrial polyps

Even asymptomatic polyps in premenopausal women are usually removed as soon as they are diagnosed, although it is still unknown how often endometrial polyps disappear spontaneously. Hysteroscopy provides an opportunity to examine the endometrial cavity and to resect endometrial polyps in all women presenting with gynecologic symptoms suspected to have endometrial polyps. There are few publications to date regarding the natural history of polyps or the factors related to their spontaneous regression. In a study involving asymptomatic women, the rate of polyp disappearance for 1 year was reported to be $28 \%$ [4]. Another study involving postmenopausal women reported that the rate of complete spontaneous polyp regression was $6.3 \%$ in a period of 28 months [5]. Thus, some polyps can regress spontaneously, and immediate polypectomy in these women may not be necessary, avoiding associated surgical and anesthetic risks. The ability to estimate which polyps might regress spontaneously would allow clinicians to determine which patients require close follow-up without a need for surgical removal.

In this retrospective study, we aimed to evaluate the rate of spontaneous polyp regression in women and to investigate the possible factors related to polyp regression.

\section{Materials and methods}

Patients who underwent operative hysteroscopy and preferred follow-up for endometrial polyps for various reasons were included in this retrospective study between January 2017 and April 2019.

\section{Patient selection}

The study group consisted of women aged between 27 and 71 years who were offered operative hysteroscopy but could not be operated in a month because of the patients' preference or other circumstances related to patient comorbidities. Fig. 1 shows the flowchart of patients who were assessed and followed up or excluded. Clinical and pathological data were obtained from the medical records. All clinical and demographic characteristics, presenting symptoms, histopathological results, and intraoperative findings of the patients were recorded.

Patients were excluded if they were lost to follow-up or were operated on within a month after the diagnosis of endometrial polyp or if they had another pathology, such as submucous myoma observed in the ultrasound or office hysteroscopy or if they were taking hormonal contracep-

197 women with endometrial polyps aged 27-71 years were decided to perform operative hysteroscopy

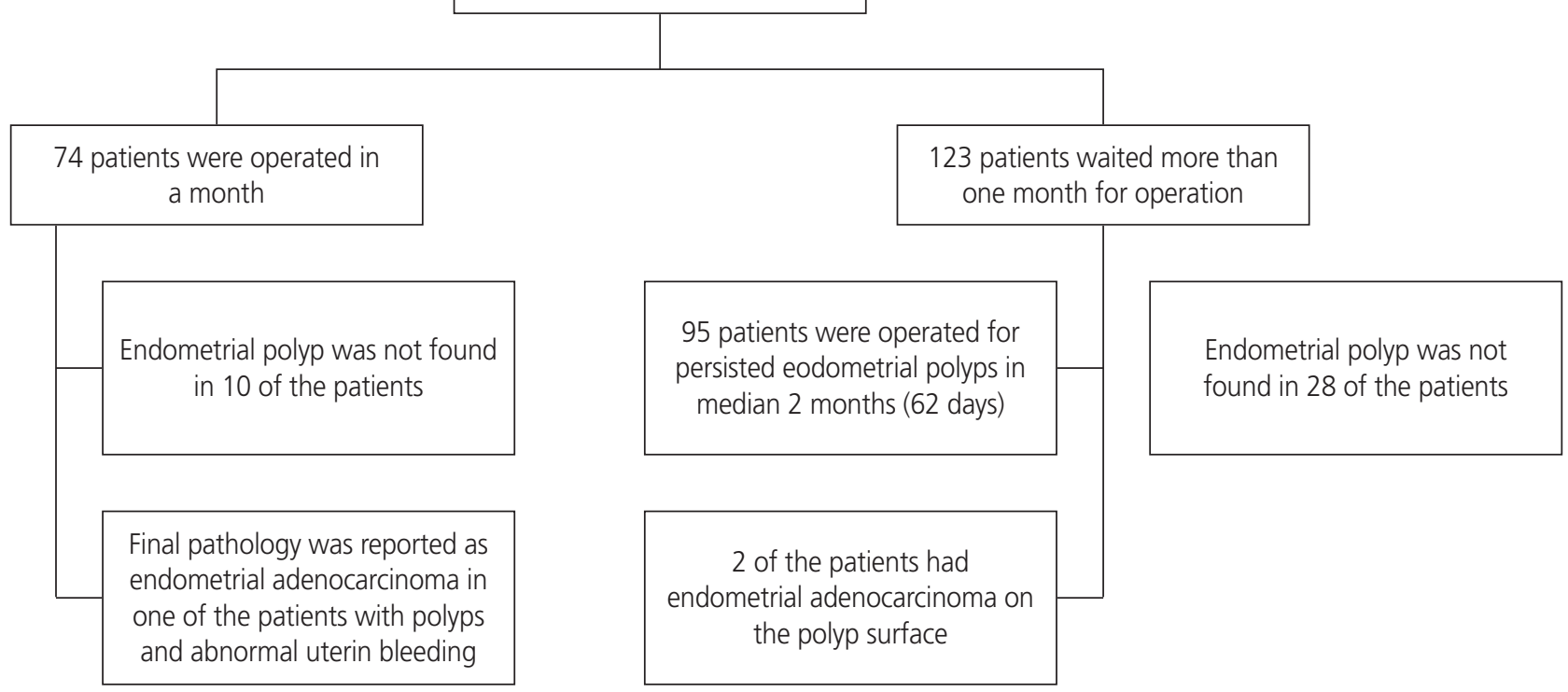

Fig. 1. Study flowchart. 


\title{
Obstetrics \& Gynecology Science
}

\author{
Vol. 64, No. 1, 2021
}

tion, tamoxifen, or hormone replacement therapy. We also excluded infertile women with endometrial polyps who were not feasible for follow-up.

The first examination of the patients was performed during the follicular phase (10-14 days after last menstrual period), which was reported as the most appropriate time period to detect endometrial polyps [5]. All scans were performed in a standardized manner. The initial and followup tests were conducted by the same expert physician for each patient. The criteria for a suspected endometrial polyp on ultrasonographic examination included a hyperechoic well-defined focal mass within the endometrial cavity with a single feeding vessel on Doppler examination [6]. Patients suspected to have more than 1 polyp were also evaluated with office hysteroscopy. Saline hydrosonography (SHG) was used in women with inadequate observation during office hysteroscopy. In women with more than 1 polyp, the size of the largest polyp was used for analysis. Each polyp was measured in 3 perpendicular planes, and their mean was used for size description $(<1 \mathrm{~cm}$, or $1-2 \mathrm{~cm}$, or $>2 \mathrm{~cm})$. Abnormal uterine bleeding was defined as heavy menstrual bleeding $(<80 \mathrm{~mL}$ ) or bleeding for more than 7 days or the presentation of bleeding between menstrual periods. Complete spontaneous regression was noted when an endometrial polyp was not detected on follow-up ultrasound or office hysteroscopy examination.

In our clinic, we only offer follow-up of premenopausal patients with asymptomatic small polyps $(<1 \mathrm{~cm})$, according to the 2012 Practice Guidelines for the Diagnosis and Management of Endometrial Polyps by the American Association of Gynecologic Laparoscopists (AAGL) [7]. Indications for operative hysteroscopy were endometrial polyps with gynecologic symptoms (postmenopausal bleeding, abnormal uterine bleeding, pelvic pain), large endometrial polyps $(>1 \mathrm{~cm})$, and postmenopausal patients with endometrial polyps. After the indication for surgery, conservative follow-up was offered to premenopausal patients due to the chance of spontaneous regression and low malignancy risk. The postmenopausal group of patients with endometrial polyps who could not be operated in a month because of factors related to older age and comorbidity were also included in the study. Endometrial sampling with a Pipelle cannula was performed in patients who were older than 40 years with abnormal uterine bleeding due to malignancy risk.

Patients with persistent polyps underwent surgery. Using an Olympus electrosurgery system (Olympus, Tokyo, Japan) with mannitol, the polyps were removed using a monopolar loop resectoscope. Histopathologic evaluation of the background endometrium was performed in premenopausal women, menopausal women, those with large polyps $(>2 \mathrm{~cm})$ or irregular or thickened endometrium, and women above 40 years of age. If the rest of the endometrial cavity was atrophic, no additional sampling was performed.

\section{Statistical analysis}

NCSS 10 (2015; NCSS, LLC, Kaysville, UT, USA) was used for statistical analysis. Normality control was performed using the Shapiro-Wilk test. The differences in continuous variables between women with regressed and non-regressed polyps were analyzed using the Mann-Whitney $U$ test. Nominal variables were evaluated with Fisher's exact probability tests, Yates corrected $\chi^{2}$ test, and Yates correction. The factors affecting regression status were determined by logistic regression analysis. All variables with $P<0.20$ were included in the logistic regression analysis. The significance limit was set at $P<0.05$.

\section{Results}

During the 2-year study period, 197 women with endometrial polyps were candidates for hysteroscopic polypectomy in our department (Fig. 1). Of these, 74 patients underwent surgery within 1 month after diagnosis. A total of 123 patients waited more than 30 days for the operation. They were followed up regularly over a median period of 62 days (range 30-360 days). The demographic characteristics and clinical properties of the study population are shown in Table 1. Of the study participants, 27 women (22\%) were postmenopausal (more than 1 year since the last menstrual bleeding), and 96 women (78\%) were premenopausal. Moreover, $64 \%$ of the women had no chronic disease other than the diagnosis of endometrial polyps. The most frequent diseases were diabetes mellitus (17\%), hypertension (17\%), hypothyroidism (11\%), and coronary artery disease $(4 \%)$. When comparing women with persistent or regressed polyps, no significant differences in median duration time, mean hemoglobin level, parity, smoking, and comorbidity were detected. Women with persistent endometrial polyps were older than women with regressed polyps (median age 45 vs. 39.5 years, $P<0.001)$. 


\section{Obstetrics \& Gynecology Science}

Semra Yuksel, et al. Regression of endometrial polyps

Most women with endometrial polyps (84\%) were reported to have gynecologic symptoms. While $83 \%$ of premenopausal women had abnormal uterine bleeding (menorrhagia or metrorrhagia), $41 \%$ of postmenopausal women had postmenopausal bleeding. Endometrial polyps were detected in
$81.3 \%(n=100)$ of patients by ultrasound, $62.6 \%(n=77)$ of patients by office hysteroscopy, and $1.6 \%(n=2)$ of patients by SHG. Endometrial sampling was performed in patients at risk for endometrial cancer. These are women older than 45 years with abnormal uterine bleeding, younger than 45 years

Table 1. Comparison of patients with regressed and persistent polyps with regard to their demographic and clinical characteristics

\begin{tabular}{|c|c|c|c|}
\hline Characteristics & $\begin{array}{l}\text { Patients with persisted polyps } \\
\qquad(n=95)\end{array}$ & $\begin{array}{l}\text { Patients with regressed polyps } \\
\qquad(n=28)\end{array}$ & $P$-value \\
\hline Age (yr) & $45.0(27-71)$ & $39.5(28-54)$ & $<0.001^{\mathrm{a})}$ \\
\hline Hemoglobin level (g/L) & $11.9 \pm 1.5$ & $11.6 \pm 2.1$ & $0.460^{b)}$ \\
\hline Duration (day) & $62(30-356)$ & $62(30-330)$ & - \\
\hline Multigravida & $83(87)$ & $24(86)$ & $0.760^{c)}$ \\
\hline Premenopausal women & $68(72)$ & $28(100)$ & $0.003^{\mathrm{d})}$ \\
\hline Postmenopausal women & $27(28)$ & 0 & - \\
\hline Smoking present & $16(17)$ & $9(32)$ & 0.130 \\
\hline Diabetes mellitus & $18(19)$ & $3(11)$ & 0.420 \\
\hline Hypertension & $18(19)$ & $3(11)$ & 0.420 \\
\hline Hypothyroidism & $10(11)$ & $4(14)$ & 0.580 \\
\hline
\end{tabular}

Values are presented as median (interquartile range), number (\%), or mean \pm standard deviation. Statistically significant $P$-values were displayed with bold characters.

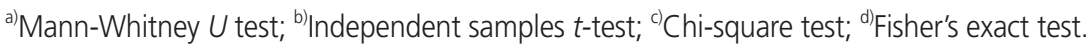

Table 2. Comparison of patients' demographic and polyps' morphological characteristics between polyps that persisted during the follow-up period and those that underwent complete spontaneous regression

\begin{tabular}{|c|c|c|c|}
\hline Patient and polyp characteristics & $\begin{array}{l}\text { Patients with persistent } \\
\text { polyps }(n=95)\end{array}$ & $\begin{array}{l}\text { Patients with regressed } \\
\text { polyps }(n=28)\end{array}$ & $P$-value ${ }^{\text {a) }}$ \\
\hline Age (yr) & $45(27-71)$ & $39.5(28-54)$ & \\
\hline$<45$ & $23(24)$ & $14(50)$ & $<0.001$ \\
\hline$\geq 45$ & $72(76)$ & $14(50)$ & 0.009 \\
\hline Polyp number (single polyp) & $40(64)$ & $15(83)$ & 0.190 \\
\hline Polyp number (multiple polyps) & $23(36)$ & $3(17)$ & - \\
\hline Polyp size by ultrasound or office hysteroscopy $(\mathrm{cm})$ & & & 0.002 \\
\hline$<1$ & $26(27)$ & $16(57)$ & \\
\hline $1-2$ & $38(40)$ & $11(39)$ & \\
\hline$>2$ & $31(33)$ & $1(4)$ & \\
\hline No complaint (asymptomatic) & $18(19)$ & $2(7)$ & 0.500 \\
\hline AUB & $56(59)$ & $24(86)$ & $<0.001$ \\
\hline Adenomyomatous polyp & $12(13)$ & 0 & - \\
\hline Endometrial hyperplasia & $2(1.6)$ & & - \\
\hline Endometrial carcinoma & $2(1.6)$ & & - \\
\hline
\end{tabular}

Statistically significant $P$-values were displayed with bold characters.

AUB, abnormal uterine bleeding.

${ }^{\text {a) } A f t e r}$ correction for comparisons, the threshold for statistical significance is $P<0.003$. 


\title{
Obstetrics \& Gynecology Science
}

\author{
Vol. 64, No. 1, 2021
}

with a history of unopposed estrogen exposure (obesity or polycystic ovary syndrome), or with postmenopausal bleeding. Further, $18.7 \%$ of patients had preoperative endometrial sampling, all of which were benign. A total of 42 patients (34\%) had polyps smaller than $1 \mathrm{~cm}$ in size, 49 patients (40\%) had polyps greater than $1 \mathrm{~cm}$ but not larger than $2 \mathrm{~cm}$ in size, and 32 patients (26\%) had polyps larger than $2 \mathrm{~cm}$ at diagnosis. Additionally, $21 \%$ of patients had more than 1 polyp at diagnosis.

Table 2 shows the comparison of women with persistent and regressed polyps with the possible factors associated with polyp regression. Endometrial polyps regressed spontaneously during follow-up in 28 women (23\%), who were all in the premenopausal period. Regressed endometrial polyps were significantly smaller at diagnosis $(<2 \mathrm{~cm})$ than others, more frequent in the premenopausal group and in women younger than 45 years $(P<0.05)$. Fig. 2 shows the regression or persistence of the polyps according to size $(<1 \mathrm{~cm}, 1-2 \mathrm{~cm}$, $>2 \mathrm{~cm}$ ) in premenopausal women. Polyp regression was more frequent in patients with abnormal uterine bleeding than in asymptomatic women $(P=0.05)$. When multiple comparisons between variables with logistic regression were performed, age ( $>45$ years) and polyp size $(>2 \mathrm{~cm}$ ) were found to be associated with endometrial polyp persistence $(P<0.01$ and $P=0.009$, respectively). The number of polyps at diagnosis was similar between the 2 groups. In the histopathologi-

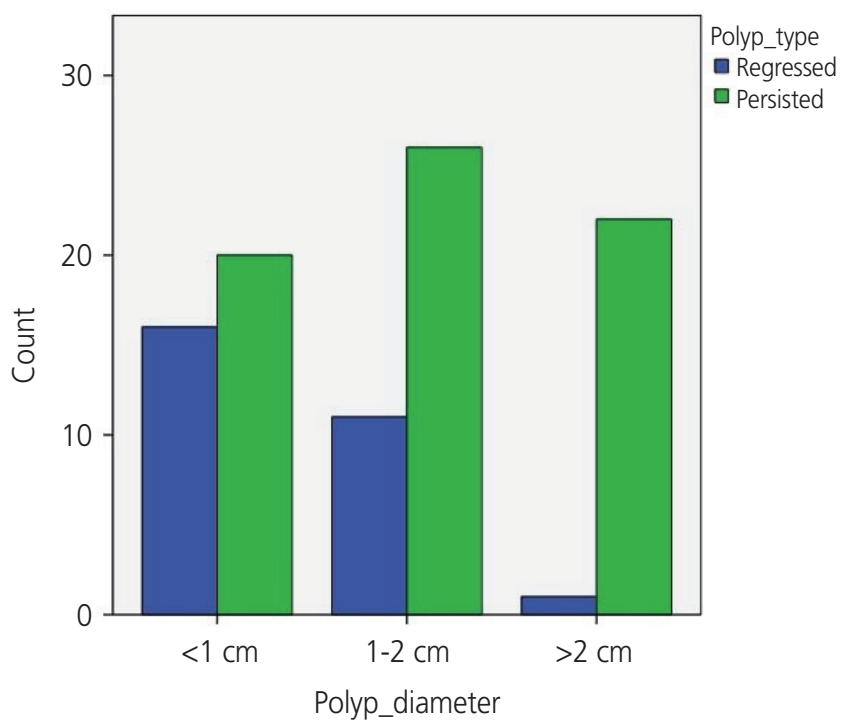

Fig. 2. The bar graph shows polyp regression and persistence rates in the premenopausal group according to the size of the endometrial polyps. cal examination of persistent polyps, we observed a $12.6 \%$ prevalence of adenomyomatous polyps. Clinically, the majority of our patients with adenomyomatous polyps presented with postmenopausal bleeding or abnormal uterine bleeding (75\%).

Ninety-five women with persistent endometrial polyps underwent hysteroscopic polypectomy in the median of 2 months. We observed no complications related to the surgical procedure. Histopathological examination revealed benign endometrial polyps in 92 women (95.8\%) and endometrial hyperplasia without atypia in 2 women (1.6\%). Endometrioid adenocarcinoma was detected at the base of the polyp in 2 patients (1.6\%). Of the 2 patients with grade 1 adenocarcinoma, 1 was 42 and the other was 71 years old. Both had polyps greater than $2 \mathrm{~cm}$ in size. No polyp was found in $22 \%$ ( $n=28$ ) of patients during hysteroscopy. Endometrial biopsy was performed in 24 patients with endometrial irregularity and abnormal uterine bleeding. There was no malignancy in the pathology report in this group.

\section{Discussion}

There is little evidence in the literature regarding the spontaneous regression rate of symptomatic endometrial polyps and related factors with the usual "see" and "treat" approach $[4,5]$. We found that the spontaneous regression rate of endometrial polyps was $23 \%$ in our study, similar to the findings of a prospective study in asymptomatic women aged 45 to 50 years during 12 months of follow-up (27\%, 8 of 31 women) [4]. DeWaay et al. [8] have previously reported a higher regression rate of endometrial polyps in a small sample size study (4 of 7 women, $57.1 \%$ ) after a longer followup period (2.4-2.7 years) than what we reported. In contrast, Wong et al. [5] found a low complete regression rate (7 of 112 women, $6.3 \%$ ) without intervention or medical treatment during a median follow-up period of 28 months. The lower regression rate in this study can be explained by the advanced age of their study population, which included a higher rate of postmenopausal women, unlike our study (62\% vs. $21 \%)$.

Our results showed that endometrial polyps smaller than $2 \mathrm{~cm}$ in premenopausal women and in those with abnormal uterine bleeding regress more frequently than the others. Polyps larger than $2 \mathrm{~cm}$ correlate with a lower possibility 


\section{Obstetrics \& Gynecology Science}

Semra Yuksel, et al. Regression of endometrial polyps

of spontaneous regression during a median of 2 months $(P<0.05)$, while there was no difference between polyps $<1 \mathrm{~cm}$ and 1-2 cm in size. Salim et al. [9] reported that endometrial polyps that were approximately $15.1 \mathrm{~mm}$ in length were less likely to show regression in 12 months than smaller polyps around $10.7 \mathrm{~mm}$. In addition, Lieng et al. [4] showed that smaller polyps (mean diameter, $10.7 \mathrm{~mm}$ ) regress more frequently than larger polyps (mean diameter, $15.1 \mathrm{~mm}$ ).

Endometrial polyps can contribute to a patient's abnormal uterine bleeding in 2 ways. In mild forms of abnormal uterine bleeding, the hypothesis is that chronic inflammation leads to vascular fragility and micro-erosions of the surface epithelium. In large pedunculated polyps, the apical portion sustains ischemic tissue necrosis and torsion of the pedicle of polyps leading to extensive thrombosis of the feeding vessels [10]. Hence, abnormal bleeding can be a symptom of polyp regression. In our study, the polyps appeared to regress more frequently in premenopausal women with abnormal uterine bleeding $(P=0.05)$. In addition, most premenopausal patients (83\%) with endometrial polyps had abnormal uterine bleeding, and the regression rate in this group was high (29\%).

Adenomyomatous polyps are characterized by the proliferation of myomatous stroma admixed with exophytic endometrial glands. We observed a high percentage of adenomyomatous polyps in the histopathological examination of persistent polyps (12.6\%). Clinically, the majority of our patients with adenomyomatous polyps presented with postmenopausal bleeding or abnormal uterine bleeding (75\%). In a recent study, the mean size of adenomyomatous polyps was reported to be $2.5 \mathrm{~cm}$, which is mostly reported as abnormal uterine bleeding, similar to our results [11]. The myomatous component or large adenomyomatous polyps may persist.

The frequency of premalignant and malignant lesions in endometrial polyps was reported to be $3.4 \%$, and there was high heterogeneity among the studies $(I, 80.5 \% ; P<0.05)$ [12]. Kilicdag et al. [13] reported the prevalence of premalignancy or malignancy as $2.2 \%$ (0.5\% hyperplasia with atypia and $1.7 \%$ endometrial adenocarcinoma) among the large sample size of premenopausal women (417 patients) with endometrial polyps. Jiang et al. [14] reported $0.6 \%$ of atypical hyperplasia and no malignancy in the premenopausal group in their study of asymptomatic women with endometrial polyps. However, the malignancy rate was found to be $0.6 \%$ in premenopausal women with abnormal uterine bleeding in a recent study [15]. In our study, we did not observe malig- nancy or atypia in asymptomatic women with endometrial polyps. The prevalence of endometrial carcinoma in women who were confirmed to have polyps was $1.6 \%$ (only 2 patients). Both patients had large endometrial polyps $(>2 \mathrm{~cm}$ ). One patient had abnormal perimenopausal bleeding and another had postmenopausal bleeding.

We did not observe any polyp regression in postmenopausal women. There are limited data on postmenopausal women with symptomatic polyps due to anxiety of malignancy [7]. Since it is known that the etiology of postmenopausal endometrial polyps is related to loss of apoptotic regulation and overexpression of estrogen and progesterone receptors, the polyps should be removed [16]. The follow-up period of postmenopausal patients in our study changed depending on the patients' preferences and comorbidities that could prevent immediate operation.

The recurrence rate of endometrial polyps after hysteroscopic polypectomy is not exactly known. In a recent prospective study, $32 \%$ of patients had endometrial polyp (EP) recurrence 1 year after polypectomy. The frequency of EP recurrence was found to be much higher in women with multiple polyps than in others (45.5\% vs. $13.4 \%$ ) [17]. We do not know the recurrence rate in our patients since the follow-up period is insufficient.

According to the $A A G L$, conservative management is reasonable, particularly for asymptomatic small polyps in premenopausal women [7]. In our clinic, we managed premenopausal asymptomatic women with small polyps conservatively due to the low risk of malignancy. If the patient complains of symptoms such as abnormal uterine bleeding or infertility, hysteroscopic polypectomy is offered even if the patient is premenopausal.

The limitation of our study was its retrospective design. Patients who had operations within a month of diagnosis were excluded from the study. Therefore, our study group was only composed of patients who preferred conservative management because of low malignancy risk or comorbidity preventing immediate operation. We were unable to followup our patients for the same length of time.

In conclusion, a certain percentage of polyps regress spontaneously, and symptomatic small polyps $(<2 \mathrm{~cm})$ may regress more frequently than others. Hence, patients who are premenopausal, particularly younger than 45 years, may not require immediate intervention. Postmenopausal women and patients with adenomyomatous polyps seem to be prone 


\section{Obstetrics \& Gynecology Science}

Vol. 64, No. 1, 2021

to persistent polyps. Conservative management is feasible depending on the patient's health status, psychological condition, and absence of risk factors for malignancy. Such an approach can potentially reduce the risk of overtreatment, prevent possible complications related to anesthesia, and eliminate the financial burden of the operation.

The optimal time for endometrial polyp regression is unknown, especially in symptomatic women with small polyps. Future studies regarding follow-up of symptomatic polyps at certain intervals with ultrasound can allow us to estimate which group of patients have a higher chance of endometrial polyp regression.

\section{Acknowledgements}

We would like to thank Sevim Purisa for the statistical analysis and Fatima Faris for language editing assistance.

\section{Conflict of interest}

No potential conflicts of interest relevant to this article were reported.

\section{Ethical approval}

This study was approved by the Ethics Committee of Gaziosmanpasa Training and Research Hospital (IRB No. 201952), confirming its adherence to the Ethical Guidelines of the Declaration of Helsinki.

\section{Patient consent}

The requirement for obtaining informed consent was waived by the ethics review board owing to the retrospective nature of the study.

\section{Funding information}

None.

\section{References}

1. Tanos V, Berry KE, Seikkula J, Abi Raad E, Stavroulis A, Sleiman $Z$, et al. The management of polyps in female reproductive organs. Int J Surg 2017;43:7-16.

2. Dreisler E, Stampe Sorensen S, Ibsen PH, Lose G. Prevalence of endometrial polyps and abnormal uterine bleeding in a Danish population aged 20-74 years. UItrasound Obstet Gynecol 2009;33:102-8.

3. Uglietti A, Buggio L, Farella M, Chiaffarino F, Dridi $D$, Vercellini $P$, et al. The risk of malignancy in uterine polyps: a systematic review and meta-analysis. Eur J Obstet Gynecol Reprod Biol 2019;237:48-56.

4. Lieng M, Istre O, Sandvik L, Qvigstad E. Prevalence, 1-year regression rate, and clinical significance of asymptomatic endometrial polyps: cross-sectional study. J Minim Invasive Gynecol 2009;16:465-71.

5. Wong M, Crnobrnja B, Liberale V, Dharmarajah K, Widschwendter $M$, Jurkovic $D$. The natural history of endometrial polyps. Hum Reprod 2017;32:340-5.

6. Valentin L. Imaging techniques in the management of abnormal vaginal bleeding in non-pregnant women before and after menopause. Best Pract Res Clin Obstet Gynaecol 2014;28:637-54.

7. American Association of Gynecologic Laparoscopists. AAGL practice report: practice guidelines for the diagnosis and management of endometrial polyps. J Minim Invasive Gynecol 2012;19:3-10.

8. DeWaay DJ, Syrop CH, Nygaard IE, Davis WA, Van Voorhis BJ. Natural history of uterine polyps and leiomyomata. Obstet Gynecol 2002;100:3-7.

9. Salim S, Won H, Nesbitt-Hawes E, Campbell N, Abbott J. Diagnosis and management of endometrial polyps: a critical review of the literature. J Minim Invasive Gynecol 2011;18:569-81.

10. Ferenczy A. Pathophysiology of endometrial bleeding. Maturitas 2003;45:1-14.

11. Strickland KC, Yuan L, Quade BJ, Nucci MR, Howitt BE. Clinicopathological and immunohistochemical features of uterine adenomyomatous polyps. Hum Pathol 2019;84:239-45.

12. Sasaki LMP, Andrade KRC, Figueiredo ACMG, Wanderley MDS, Pereira MG. Factors associated with malignancy in hysteroscopically resected endometrial polyps: a systematic review and meta-analysis. J Minim Invasive Gynecol 


\section{Obstetrics \& Gynecology Science}

Semra Yuksel, et al. Regression of endometrial polyps

2018;25:777-85.

13. Kilicdag EB, Haydardedeoglu B, Cok T, Parlakgumus $A H$, Simsek E, Bolat FA. Polycystic ovary syndrome and increased polyp numbers as risk factors for malignant transformation of endometrial polyps in premenopausal women. Int J Gynaecol Obstet 2011;112:200-3.

14. Jiang T, Yuan Q, Zhou Q, Zhu Y, Lv S, Cao Y, et al. Do endometrial lesions require removal? A retrospective study. BMC Womens Health 2019;19:61.

15. De Azevedo JM, De Azevedo LM, Freitas F, Wender MC.
Endometrial polyps: When to resect? Arch Gynecol Obstet 2016;293:639-43.

16. Pereira AK, Garcia MT, Pinheiro W, Ejzenberg D, Soares $J \mathrm{M} \mathrm{Jr}$, Baracat EC. What is the influence of cyclooxygenase-2 on postmenopausal endometrial polyps? Climacteric 2015;18:498-502.

17. Gu F, Zhang H, Ruan S, Li J, Liu X, Xu Y, et al. High number of endometrial polyps is a strong predictor of recurrence: findings of a prospective cohort study in reproductive-age women. Fertil Steril 2018;109:493-500. 